\title{
ADENOSINE TRIPHOSPHATE-DEPENDENT POTASSIUM CHANNEI MODULATION AND CARDIOPLEGIA-INDUCED PROTECTION OF HUMAN ATRIAL MUSCLE IN AN IN VITRO MODEL OF MYOCARDIAL STUNNING
}

Francesco Monti, MD

Katsunori Iwashiro, MD

Sandra Picard, $\mathrm{PhD}$

Anna Criniti, PhD

Saverio La Francesca, MD

Giovanni Ruvolo, MD

Ugo Papalia, MD

Pietro Paolo Campa, MD

Benedetto Marino, MD

Paolo Emilio Puddu, MD
Objectives: Although adenosine triphosphate-dependent potassium channel openers have been shown to enhance cardioplegic protection in animal myocardium, there is a lack of data on human cardiac tissues. We aimed at determining, on human atrial muscle, whether adenosine triphosphatedependent potassium channels are involved in protection caused by highpotassium cardioplegia and whether adenosine triphosphate-dependent potassium channel activation might improve cardioplegic protection in an in vitro model of myocardial stunning.

Methods: Human atrial trabeculae were obtained from adult patients undergoing cardiac operations. In an organ bath at $37^{\circ} \mathrm{C}$, the preparations were subjected to 60 minutes of hypoxia at a high stimulation rate either in Tyrode solution (control, $\mathrm{n}=17$ ) or in St Thomas' Hospital solution without additives $(\mathrm{n}=6)$ or associated with $100 \mathrm{nmol} / \mathrm{L}$ bimakalim $(\mathrm{n}=7)$ or $1 \mu \mathrm{mol} / \mathrm{L}$ glibenclamide $(n=7)$, followed by 60 minutes of reoxygenation and 15 minutes of positive inotropic stimulation with $1 \mu \mathrm{mol} / \mathrm{L}$ dobutamine.

Results: Atrial developed tension was reduced by hypoxia to $27 \% \pm 5 \%$ of baseline and incompletely recovered after reoxygenation to $38 \% \pm 7 \%$, whereas dobutamine restored contractility to $74 \% \pm 7 \%$ of basal values. St Thomas' Hospital solution with or without bimakalim improved developed tension after reoxygenation and dobutamine $(P<.0001 \mathrm{vs}$ control), whereas glibenclamide inhibited these protective effects of cardioplegic arrest $(P=$ .001 vs St Thomas' Hospital solution). After reoxygenation, the protective effect of bimakalim disappeared at a high pacing rate (400- and 300-ms cycle length) but recovered during dobutamine superfusion.

Conclusions: Adenosine triphosphate-dependent potassium channels are likely involved in the cardioprotective effects of cardioplegia in human atrial trabeculae and adenosine triphosphate-dependent potassium channel activation with bimakalim used as an additive to cardioplegia enhanced protection. (J Thorac Cardiovasc Surg 2000;119:842-8)
From the Laboratory of Cardiovascular Pharmacology, Department of Cardiac Surgery and Second Section of Cardiology, University of Rome "La Sapienza," Rome, Italy.

Supported in part by Ministero dell'Università e della Ricerca Scientifica, Rome (Ricerche di Ateneo 145/1997) and by Cardioricerca, Rome, Italy. Dr Wagner from E. Merck, Darmstadt, Germany, provided a gift of bimakalim used in this study.

Received for publication April 20, 1999; revisions requested June 3, 1999; revisions received Dec 1, 1999; accepted for publication Dec 7, 1999.

Address for reprints: Paolo Emilio Puddu, MD, FESC, FACC, Istituto di Chirurgia del Cuore e Grossi Vasi, II Cattedra di Cardiologia, Università degli Studi di Roma "La Sapienza," Viale del Policlinico, 155, Rome 00161, Italy (E-mail: puddu.pe @iol.it).

Copyright (C) 2000 by The American Association for Thoracic Surgery.

0022-5223/2000 $\$ 12.00+0 \quad \mathbf{1 2 / 1 / 1 0 4 8 7 8}$

doi: $10.1067 / \mathrm{mtc} .2000 .104878$
C ardioplegic arrest provides essential cardioprotection Muring cardiac operations, and advantages of continuous warm blood cardioplegia have been advanced for minimizing ischemia and avoiding risks related to hypothermia. However, postoperative ventricular dysfunction and injury caused by prolonged cardiac arrest led to the development of additional cardioprotective strategies. ${ }^{1,2}$ Adenosine triphosphate-dependent potassium $\left(\mathrm{K}_{\text {ATP }}\right)$ channel openers have been shown to limit contractile dysfunction, ${ }^{3-5}$ infarct size, ${ }^{6}$ and cellular energy depletion $^{7,8}$ caused by ischemia-reperfusion. Moreover, experimental studies carried out on the rabbit, ${ }^{9}$ pig, ${ }^{10}$ guinea pig, ${ }^{11,12}$ and rat $^{13}$ have demonstrated benefits of $\mathrm{K}_{\mathrm{ATP}}$ channel activators to improve myocardial preservation provided by both cold and warm cardioplegia. 


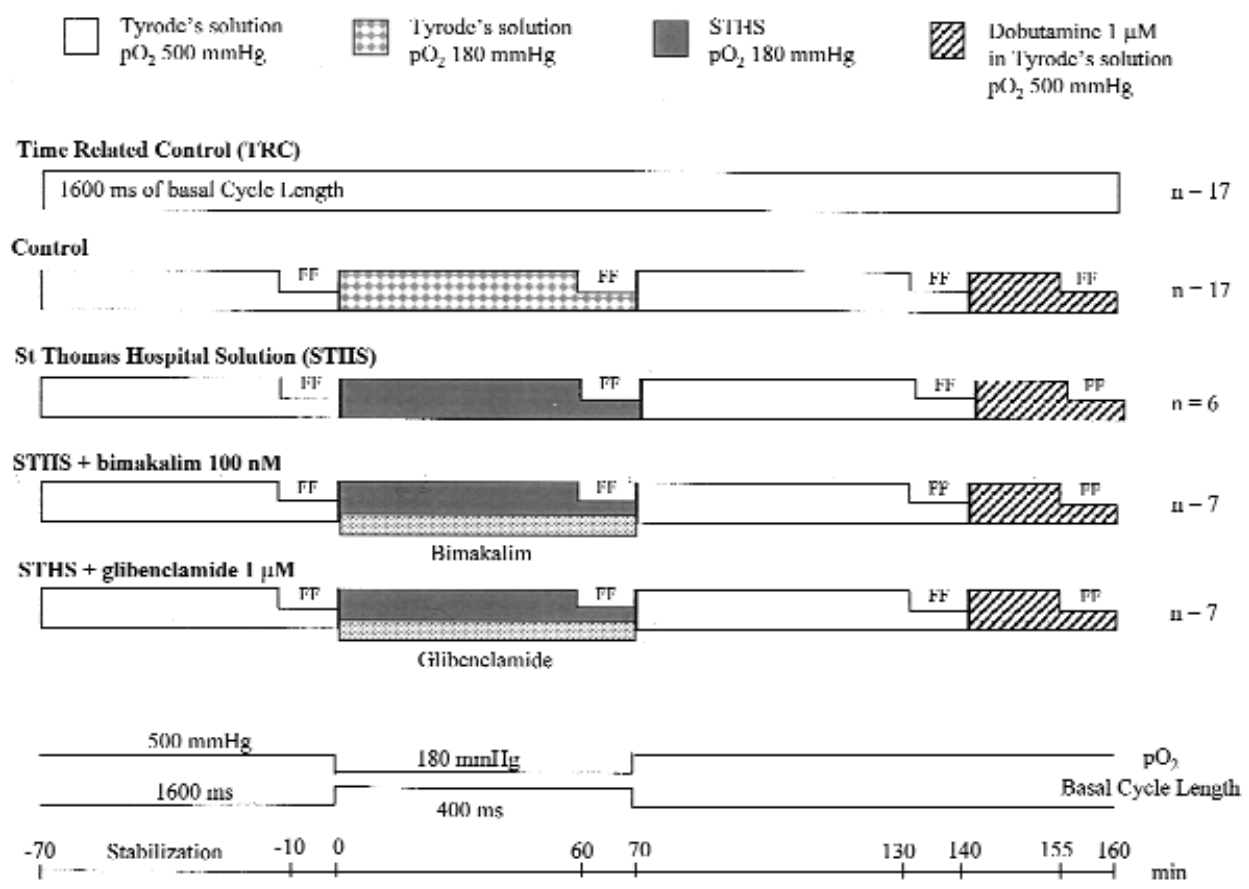

Fig 1. Experimental protocol for investigation of protective effects of normothermic $\left(37^{\circ} \mathrm{C}\right)$ cardioplegia (STHS), either alone or associated with $\mathrm{K}_{\mathrm{ATP}}$ channel modulators, on human atrial trabeculae in an in vitro model of myocardial stunning. FF relationships were studied after each different experimental phase. Hypoxia was performed at a high pacing rate (400-ms CL).

The susceptibility to ischemic injury and responsiveness to myocardial protection, however, differ among mammals, ${ }^{14}$ and the efficacy of a $\mathrm{K}_{\text {ATP }}$ channel opener on cardiac muscle may differ between human and other species, as we demonstrated in a previous work. ${ }^{15}$ Considering that the goal of experimental studies on cardioplegia is use in the human myocardium and determination of the potential benefits that patients might find in strategies aimed at reducing postoperative myocardial stunning, confirmation on human cardiac muscle of protective action of $\mathrm{K}_{\mathrm{ATP}}$ channel openers as additives to cardioplegic solution is of interest.

We aimed at determining whether $\mathrm{K}_{\text {ATP }}$ channels are implicated in the cardioprotective effects of cardioplegic arrest with St Thomas' Hospital solution (STHS) superfusion on human atrial trabeculae and whether $\mathrm{K}_{\text {ATP }}$ channel activation may enhance the benefits of cardioplegia against myocardial stunning induced by hypoxia-reoxygenation. For this, we used the selective $\mathrm{K}_{\text {ATP }}$ channel blocker glibenclamide and the $\mathrm{K}_{\text {ATP }}$ channel opener bimakalim as additives to the cardioplegic solution during the hypoxic phase. Normothermic instead of cold cardioplegia was selected to prevent complicating factors related to temperature shift in the analysis of contractility changes among experimental groups. $^{12}$

\section{Patients and methods}

Preparation. Informed consent was obtained from 41 adult patients (68\% male and $32 \%$ female subjects) undergoing elective cardiac operations, whose ages ranged from 23 to 79 years ( $57 \pm 11$ years) and who had coronary artery disease (59\%), rheumatic valve disease (34\%), or congenital lesions (7\%). Patients were routinely taking cardioactive drugs according to standard prescriptions. Ethical considerations prevented us from stopping these drugs more than 24 hours before the operations. Exclusion criteria were arrhythmia, right ventricular failure, and antiarrhythmic or oral hypoglycemic medication. Premedication, given 1 hour before induction of anesthesia, usually consisted of diazepam, antibiotic (cephalotine), and aprotinin. General anesthesia was then induced with diazepam, fentanyl, pancuronium, and sometimes nitrous oxide.

A sample of the right atrial appendage (approximately 1 $\mathrm{cm}^{2}, 500-1000 \mathrm{mg}$ ) was removed and immersed in preoxygenated modified Tyrode solution $(\mathrm{NaCl}, 120 \mathrm{mmol} / \mathrm{L} ; \mathrm{KCl}$, $4 \mathrm{mmol} / \mathrm{L} ; \mathrm{CaCl}_{2}, 2.7 \mathrm{mmol} / \mathrm{L} ; \mathrm{MgCl}_{2}, 1.1 \mathrm{mmol} / \mathrm{L}$; $\mathrm{NaHCO}_{3}, 25.7 \mathrm{mmol} / \mathrm{L} ; \mathrm{NaH}_{2} \mathrm{PO}_{4}, 1.8 \mathrm{mmol} / \mathrm{L}[\mathrm{pH} 7.4]$; and glucose, $11 \mathrm{mmol} / \mathrm{L}$ ) at room temperature. ${ }^{5,15-18}$ Free-running trabeculae were isolated and fixed to a precalibrated force 


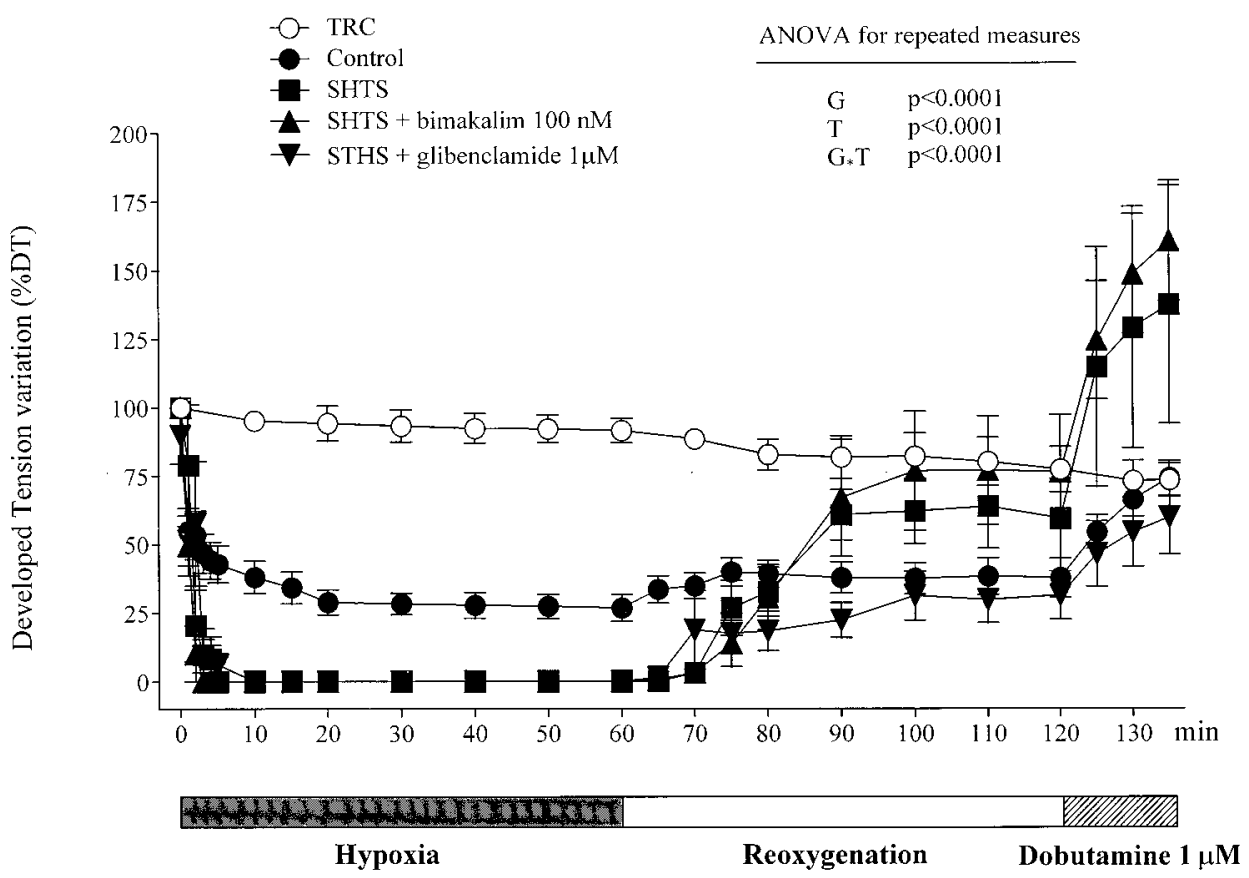

Fig 2. Effects of hypoxia-reoxygenation and dobutamine challenge on human atrial contractility. DT variations are expressed as means \pm SEM. $P$ values refer to ANOVA for repeated measures performed for the 4 hypoxiarelated groups: control, STHS, STHS plus bimakalim, and STHS plus glibenclamide. TRCs are included for visual comparative purposes. Note highly significant $P$ values for group $(\mathrm{G})$, time $(\mathrm{T})$ and group $\cdot$ time $\left(\mathrm{G}^{*} \mathrm{~T}\right)$ factors. Note marked positive inotropic action of dobutamine in preparations subjected to cardioplegic arrest, either alone or in the presence of $100 \mathrm{nmol} / \mathrm{L}$ bimakalim, whereas $1 \mu \mathrm{mol} / \mathrm{L}$ glibenclamide inhibited protective effects of cardioplegia after hypoxia.

transducer (TRN001; Kent Scientific Corporation) in an organ bath, where the preparation was superfused at 5 $\mathrm{mL} / \mathrm{min}$ with Tyrode solution gassed with $95 \%$ oxygen and $5 \%$ carbon dioxide $\left(\mathrm{Po}_{2}, 500 \mathrm{~mm} \mathrm{Hg}\right.$ measured at $755 \mathrm{~mm}$ $\mathrm{Hg}$ of barometric pressure) and gradually warmed up (circulating thermostat-regulated bath: Polystat 86602, Bioblock Scientific) to $37^{\circ} \mathrm{C}$.

Stimulation and recordings. The muscle was stimulated at $1600 \mathrm{~ms}$ of basal cycle length (CL) by means of a bipolar Teflon-coated $99.99 \%$ silver wire electrode (AG-15T, 0.375 $\mathrm{mm}$ in diameter; PHYMEP sarl). Square pulses of 1-ms duration and 4-mA intensity were delivered by an orthorhythmic stimulator (Explorer 1000, VPA Medical). The trabecula was lengthened to the top of its length-tension curve. Isometric force development was monitored on a digital memory oscilloscope (Tektronix 2230, Tektronix Inc), and data were digitized at a sampling frequency of $8 \mathrm{KHz}$ (Datapac 13.2, Biologic). The software automatically measured developed tension (DT) and time to peak tension. After the experiment, the contracting trabecular portion was dried and weighed on a precise balance (Sartorius BA 110S, Sartorius AG).

Experimental protocol (Fig 1). In a time-related control group (TRC group, $\mathrm{n}=17$ ), we assessed the time-dependent contractility loss of trabecular strips stimulated at 1600-ms
CL. Thereafter the Paradise test ${ }^{19}$ was performed in 10 preparations included in the latter group, changing 95\% oxygen and $5 \%$ carbon dioxide in Tyrode solution to $80 \%$ oxygen, $5 \%$ carbon dioxide, and $15 \%$ nitrogen for 15 minutes. Another 17 trabeculae were subjected to 60 minutes of hypoxia at $400-\mathrm{ms}$ CL by superfusion with nonoxygenated Tyrode solution $\left(\mathrm{Po}_{2} 180 \mathrm{~mm} \mathrm{Hg}\right)$ and then returned to normal for 60 minutes (reoxygenation phase), after which they were subjected to $1 \mu \mathrm{mol} / \mathrm{L}$ dobutamine for 15 minutes. The same protocol was achieved for another 20 preparations undergoing the hypoxic phase at a high pacing rate under normothermic cardioplegia by superfusion with nonoxygenated hyperkalemic STHS,${ }^{20}$ either without additive (STHS, $n=6$ ) or in the presence of $100 \mathrm{nmol} / \mathrm{L}$ bimakalim (E. Merck Laboratories; $\mathrm{n}=7$ ) or $1 \mu \mathrm{mol} / \mathrm{L}$ glibenclamide prediluted in dimethylsulfoxide $0.01 \%$ (Sigma Chemical Co; $\mathrm{n}=7$ ). At $0.01 \%$, dimethylsulfoxide $0.0 \%$ had no significant effect on human atrial contractility. The composition of STHS was as follows: $\mathrm{NaCl}, 110 \mathrm{mmol} / \mathrm{L} ; \mathrm{KCl}, 16 \mathrm{mmol} / \mathrm{L} ; \mathrm{CaCl}_{2}, 1.2$ $\mathrm{mmol} / \mathrm{L} ; \mathrm{MgCl}_{2}, 16 \mathrm{mmol} / \mathrm{L}$; and $\mathrm{NaHCO}_{3}, 10 \mathrm{mmol} / \mathrm{L}(\mathrm{pH}$ 7.8). High stimulation rate (400-ms CL) was used during the hypoxic phase to raise the severity of hypoxia, leading to stunned human atrial muscle. ${ }^{5,16,17}$ Stimulation was continued during cardioplegia to maintain the experimental condi- 


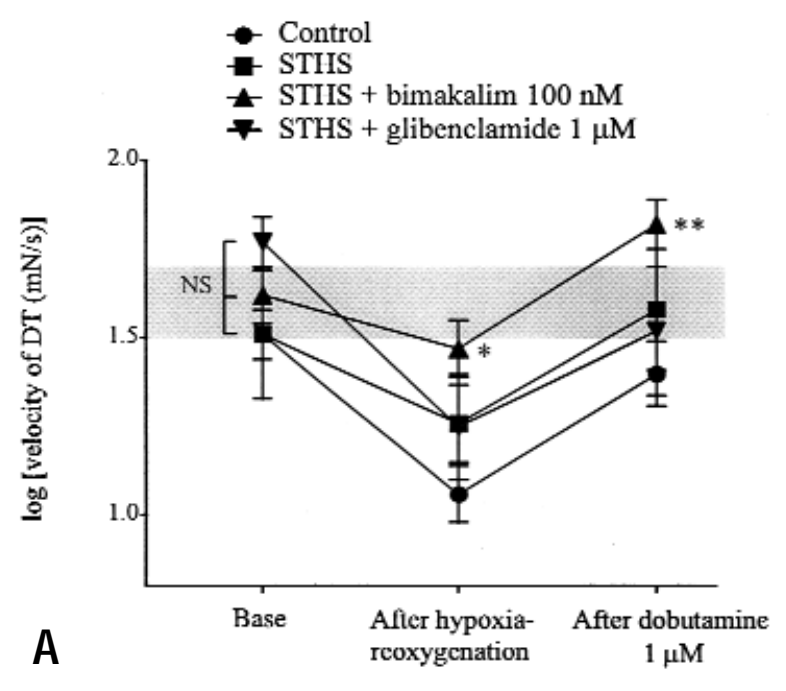

- Base

- After dobutamine $1 \mu \mathrm{M}$

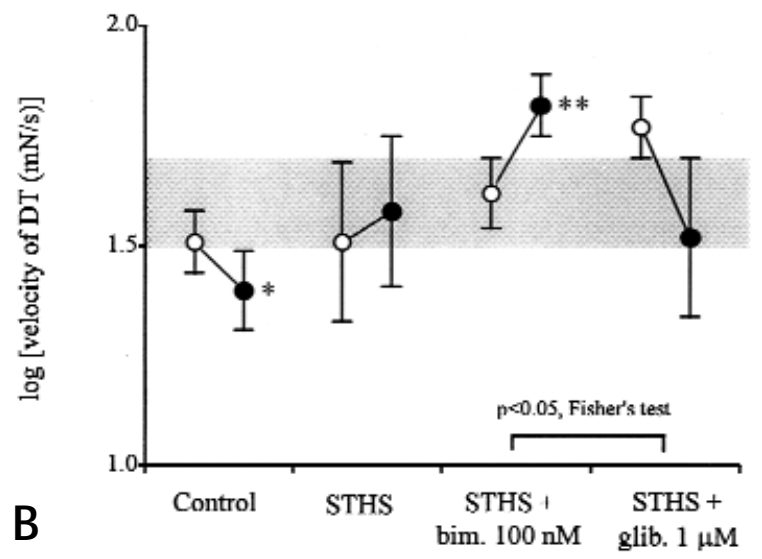

Fig 3. Changes of velocity of tension developed by human atrial trabeculae after hypoxia-reoxygenation and dobutamine challenge. Values of $\log$ [velocity of DT] are expressed as means \pm SEM. For comparison, $95 \%$ confidence intervals of basal values for all 54 preparations included in the randomized study are shown in gray. $\mathbf{A}, * P<.05$ and $* * P<.01$ versus control, Student $t$ test with Bonferroni correction. Note that $100 \mathrm{nmol} / \mathrm{L}$ bimakalim added to cardioplegic solution significantly improved the velocity of DT after hypoxiareoxygenation and dobutamine challenge. $\mathbf{B}, * P<.05$ and $* * P<.005$ versus base, Student $t$ test for paired data. Note that velocity of DT was decreased after dobutamine challenge when $1 \mu \mathrm{mol} / \mathrm{L}$ glibenclamide was associated with cardioplegia, and conversely it was improved in the STHS plus bimakalim group $(P<.05$, Fisher exact test).

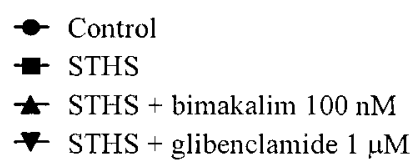

After reoxygenation

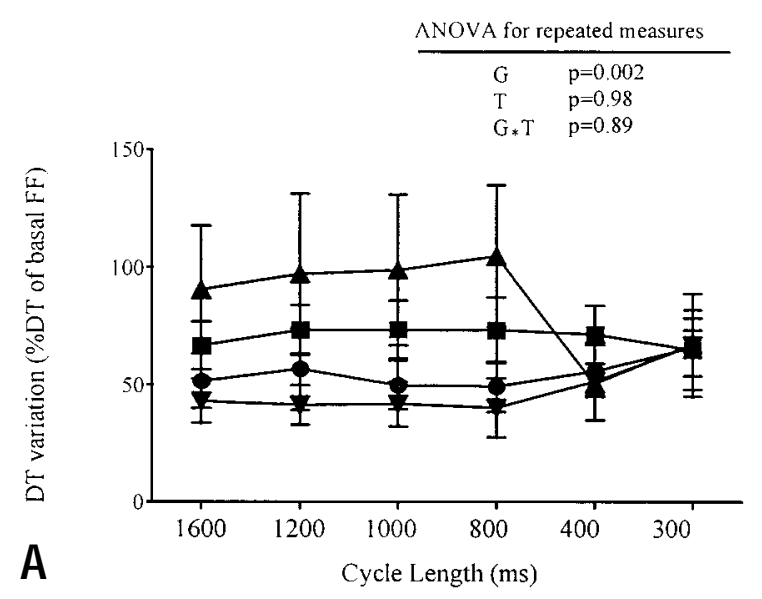

After dobutamine $1 \mu \mathrm{M}$

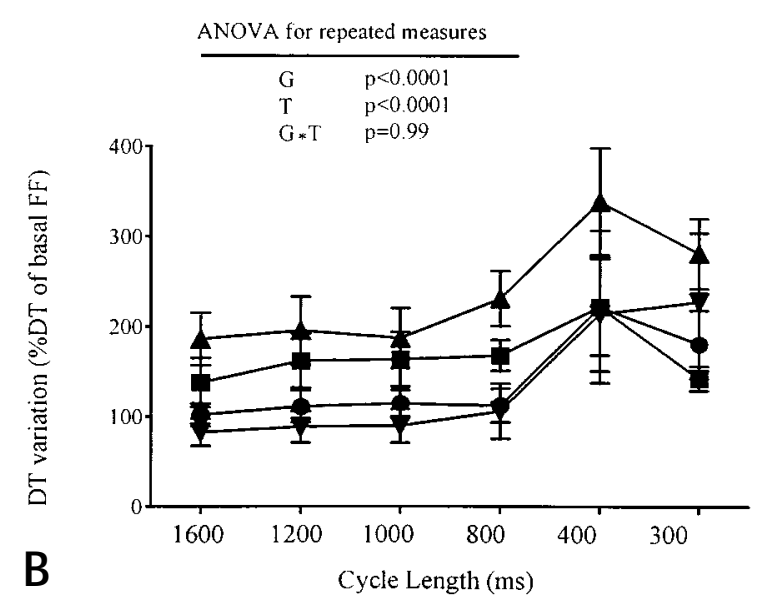

Fig 4. Changes in FF relationships of human atrial trabeculae after reoxygenation (A) and dobutamine challenge (B) in control and STHS-related groups. Developed tension variation $(\% D T)$ of DT measured during basal FF at corresponding cycle length is expressed as means \pm SEM. $P$ values refer to ANOVA for repeated measures performed for the 4 groups. Note higher FF-related developed tension variation after cardioplegic treatment, either alone or in the presence of 100 $\mathrm{nmol} / \mathrm{L}$ bimakalim, than in the control and STHS plus glibenclamide groups, which fits with improved human atrial contractility, as illustrated in Fig 2. Note that the protective effect of STHS plus bimakalim after reoxygenation disappeared at the high pacing rate (A), whereas after dobutamine treatment (B), there was no such interference. 
Table I. Basal characteristics (pacing, 1600-ms $C L ; 37^{\circ} \mathrm{C}$ ) of human atrial trabeculae used in the randomized study

\begin{tabular}{|c|c|c|c|c|c|c|c|}
\hline Variables & $\begin{array}{c}\text { Total } \\
(n=54)\end{array}$ & $\begin{array}{c}\text { TRC } \\
(n=17)\end{array}$ & $\begin{array}{l}\text { Control } \\
(n=17)\end{array}$ & $\begin{array}{l}\text { STHS } \\
(n=6)\end{array}$ & $\begin{array}{c}\text { STHS + } \\
\text { bimakalim } \\
100 \mathrm{nmol} / \mathrm{L} \\
(n=7)\end{array}$ & $\begin{array}{c}\text { STHS }+ \\
\text { glibenclamide } \\
1 \mu \mathrm{mol} / \mathrm{L} \\
(n=7)\end{array}$ & $\mathrm{P}$ values \\
\hline Age of patients (y) & $57 \pm 11(\mathrm{n}=41)$ & $55 \pm 14$ & $58 \pm 14$ & $56 \pm 6$ & $54 \pm 8$ & $62 \pm 6$ & .8 \\
\hline Mass (mg) & $29 \pm 19$ & $32 \pm 23$ & $31 \pm 23$ & $28 \pm 13$ & $20 \pm 7$ & $23 \pm 6$ & .6 \\
\hline Length (mm) & $5.5 \pm 2.2$ & $6.1 \pm 2.7$ & $5.8 \pm 2.7$ & $5.8 \pm 1.2$ & $4.3 \pm 0.5$ & $4.6 \pm 0.8$ & .3 \\
\hline Cross-sectional area $\left(\mathrm{mm}^{2}\right)$ & $2.6 \pm 2.3$ & $2.9 \pm 2.6$ & $2.8 \pm 2.6$ & $3.0 \pm 2.3$ & $1.5 \pm 1.2$ & $2.1 \pm 1.3$ & 6 \\
\hline $\mathrm{DT}(\mathrm{mN})$ & $6.8 \pm 4.9$ & $9.3 \pm 5.8$ & $5.1 \pm 4.6$ & $5.3 \pm 4.2$ & $5.5 \pm 2.1$ & $7.4 \pm 3.5$ & .09 \\
\hline $\operatorname{velDT}(\mathrm{mN} / \mathrm{s})^{*}$ & $57 \pm 39$ & $76 \pm 48$ & $45 \pm 38$ & $44 \pm 31$ & $44 \pm 17$ & $63 \pm 25$ & .12 \\
\hline $\mathrm{DT}_{\mathrm{i}}\left(\mathrm{mN} / \mathrm{mm}^{2}\right) \dagger$ & $4.6 \pm 4.1$ & $6.2 \pm 5.2$ & $3.2 \pm 3.0$ & $2.2 \pm 1.5$ & $5.7 \pm 3.5$ & $4.7 \pm 3.7$ & .11 \\
\hline $\operatorname{velDT}_{\mathrm{i}}\left(\mathrm{mN} / \mathrm{s} \cdot \mathrm{mm}^{2}\right) \dagger$ & $40 \pm 35$ & $51 \pm 42$ & $30 \pm 29$ & $19 \pm 15$ & $49 \pm 31$ & $44 \pm 39$ & .2 \\
\hline
\end{tabular}

Data are expressed as means \pm SD. $P$ values refer to analysis of variance among the 5 groups. $D T$, Developed tension; velDT, Velocity of developed tension; $D T_{i}$, indexed DT; velDT, indexed velDT.

* velDT was measured as DT/time to peak tension.

$\dashv \mathrm{DT}_{\mathrm{i}}$ and velDT $\mathrm{i}$ were measured as DT/cross-sectional area and velDT/cross-sectional area, respectively.

tions similarly to the other groups (TRC and control groups). A previous study showed that the in vitro contractile protection afforded by STHS was independent of pacing during cardioplegic arrest. ${ }^{12}$ As previously discussed, ${ }^{5,17}$ in this model the stunning phenomenon was disclosed by $1 \mu \mathrm{mol} / \mathrm{L}$ dobutamine challenge, testing the reversibility of the hypoxia/reoxygenation-induced contractile dysfunction. After each experimental phase, the force-frequency (FF) relationship was studied by decreasing stimulation CL from $1600 \mathrm{~ms}$ to 1200 , 1000, 800, 400, and 300 ms. $^{12,17}$

Statistics. Data shown in Table I are expressed as means \pm $\mathrm{SD}$, and data shown in Figs 1 to 4 and text are expressed as means \pm SEM. Analysis of variance (ANOVA) was performed to compare basal characteristics of preparations (Table I, 1-way ANOVA) and DT variations among groups (Figs 2 and 4, ANOVA for repeated measures). A variable was created to index trabecular number and thus account for the lack of independence caused by two trabeculae from the same patient in 13 of 54 preparations. Covariance for this variable did not, however, add any statistical contribution in the above-mentioned repeated measures ANOVA models where it was tested (BMDP-5V). The Student $t$ test with Bonferroni correction, the Student $t$ test for paired values, and the Fisher exact test were used for analysis of changes in log [velocity of DT] (Fig 3).

\section{Results}

Characteristics of human atrial trabeculae. Basal characteristics of the human atrial trabeculae used in this randomized study are summarized in Table I.

DT of atrial preparations exposed to oxygenated Tyrode solution (TRC group) decreased to $91 \% \pm 5 \%$ after 60 minutes and to $73 \% \pm 7 \%$ after 135 minutes (Fig 2), corresponding to an attrition rate of $9 \%$ during the first hour and $15 \%$ per hour thereafter. After 15 minutes of the Paradise test, trabecular DT was reduced to $74 \% \pm 4 \%$ of DT values measured before the test.

Effects of cardioplegia and $K_{\text {ATP }}$ channel modulators on human trabecular contractility during hypoxia-reoxygenation and dobutamine challenge. After 60 minutes of hypoxia at a high pacing rate (Fig 2 , control), DT was lessened to $27 \% \pm 5 \%$ of basal values and recovered slightly only after reoxygenation to $38 \% \pm 7 \%$ before reaching $74 \% \pm 7 \%$ of basal DT after dobutamine, and this was similar to values measured in the TRC group. After cardioplegic arrest, during reoxygenation and dobutamine challenge, DT was significantly improved in the STHS and STHS plus bimakalim groups (both $P<.0001$ versus control), whereas the percentage of DT observed in the STHS plus glibenclamide group was similar to that found in the control group $(P=.12)$, demonstrating that glibenclamide inhibited the protective effect of cardioplegic arrest $(P=.001$ vs STHS). Also, on velocity of DT, bimakalim lessened the decrease induced by hypoxia-reoxygenation (Fig 3,A) and enhanced velocity of DT after dobutamine (Fig 3, A and $B$ ), whereas velocity of DT was reduced in the control and STHS plus glibenclamide groups compared with basal values (Fig 3, B).

FF relationships. Before hypoxia, human atrial trabeculae exhibited a slight positive FF relationship as CL decreased until $800 \mathrm{~ms}$, and then depressed DT was seen at the high pacing rate. At low frequency, the FF relationship became negative after hypoxia $(P=.004$ vs baseline) and returned to positive after reoxygenation. After dobutamine, no DT reduction occurred at the highest stimulation frequencies $(P<.005$ vs baseline $)$. 
After reoxygenation (Fig 4, A), the improved DT observed at the low pacing rate in the STHS plus bimakalim group $(P<.005$ vs control) disappeared at rapid pacing (400- and 300-ms CL). After $1 \mu \mathrm{mol} / \mathrm{L}$ dobutamine (Fig 4, B), at short CL, all groups showed DT values higher than DT values obtained during basal FF at corresponding CL $(P<.0001$ for time factor), and the enhanced DT induced by STHS plus bimakalim treatment remained during the high pacing rate also.

\section{Discussion}

This in vitro study shows that (1) $\mathrm{K}_{\text {ATP }}$ channels are likely involved in the cardioprotective effects of cardioplegic arrest in stunned human atrial muscle because the contractile protection was inhibited by glibenclamide and (2) $\mathrm{K}_{\mathrm{ATP}}$ channel activation by bimakalim, used as an additive of STHS, may enhance the human atrial protection caused by cardioplegic arrest. This latter additional benefit was, however, abolished by the high pacing rate after hypoxia-reoxygenation but was present after dobutamine challenge, even at rapid pacing. Changes in FF relationship were superposable to variations reported previously, ${ }^{17}$ showing that the negative inotropic action of a high pacing rate (400- and 300-ms CL), likely because of dramatic shortening of human atrial action potential duration, ${ }^{17,18}$ consists of a normal physiologic adaptation of human atrial contractile function to rapid pacing. More interesting were the negative FF relationships induced by hypoxia and then reversed after reoxygenation and the abolition of the negative inotropic action of the high pacing rate by dobutamine, as observed in the rabbit heart. ${ }^{21}$ Considering that our findings in human cardiac tissue arise from a model of normothermic continuous STHS delivery, it will be important to confirm the additional protective effects of bimakalim during other cardioplegic methods, such as cold cardioplegia, because it has been reported extensively, although only in animal preparations. ${ }^{9-12}$

Although data suggest that $\mathrm{K}_{\text {ATP }}$ channels are likely involved in cardioprotective mechanisms related to normothermic cardioplegia in human atrial myocardium, it is unclear whether sarcolemmal $\mathrm{K}_{\mathrm{ATP}}$ channels alone are implicated or whether the mitochondrial channels also may play a role. A recent animal study showed that diazoxide, a specific mitochondrial $\mathrm{K}_{\text {ATP }}$ opener, may exert cardioprotective effects, whereas 5-OHdecanoate, a mitochondrial $\mathrm{K}_{\mathrm{ATP}}$ blocker, may block cardioprotection. ${ }^{22}$ Animal studies already reported benefits with other $\mathrm{K}_{\text {ATP }}$ channel openers as additives of cardioplegic solutions ${ }^{9,10}$ and particularly advantages of nicorandil. ${ }^{11-13,23}$ We chose bimakalim, which exerts selective $\mathrm{K}_{\text {ATP }}$ channel activating action, as opposed to nicorandil, which also possesses nitrate-related properties. In addition, we used a relatively low concentration $(100 \mathrm{nmol} / \mathrm{L})$ of bimakalim on the basis of the previous studies demonstrating protective effects of bimakalim on human atrial contractile function ${ }^{5}$ at concentrations $(10-100 \mathrm{nmol} / \mathrm{L})$ devoid of negative inotropic action and depressant effect on human atrial action potential duration., ${ }^{5,15}$ Indeed, it is important that additive cardioprotection may be obtained in the absence of action potential changes, thus ruling out potential proarrhythmic risks related to $\mathrm{K}_{\mathrm{ATP}}$ channel activators. ${ }^{24,25}$ Moreover, the bimakalim concentration used here may be considered relevant for the clinical setting. Senior and associates $^{26}$ reported bimakalim plasmatic concentrations of about $50 \mathrm{nmol} / \mathrm{L}$ in normal volunteers. Further studies are now needed to clarify the mechanisms involved in the bimakalim-induced protection during cardioplegia. In view of the strong pharmacologic evidence that $\mathrm{K}_{\text {ATP }}$ channels are involved, mitochondrial $\mathrm{K}_{\mathrm{ATP}}$ channel is a strong candidate for the putative end effector of bimakalim-induced benefits ${ }^{27}$ because additive protection was obtained during cardioplegic arrest and therefore in absence of any contractile and electrical activity.

The additional cardioprotective effects of bimakalim disappeared during the high pacing rate just after hypoxia-reoxygenation, whereas positive inotropic stimulation with dobutamine restored these effects. These findings may suggest that additional benefits of $\mathrm{K}_{\text {ATP }}$ channel activation might be overshadowed in the presence of high heart rate, arrhythmic events, or both after hypoxia-reoxygenation where contractile function is about to recover. Although caution is needed when extrapolating in vitro findings to clinical situations, these data support the usefulness of FF relationship studies when investigating the effects of $\mathrm{K}_{\mathrm{ATP}}$ channel openers. Otherwise, the restoration of bimakalim's protective effects by dobutamine at high pacing may be due to the positive inotropic stimulation within cardiac cells because dobutamine was able to revert to positive the negative part of the basal FF relationship in accordance with data previously obtained from terminally failing human ventricular myocardium. ${ }^{28}$ Further studies are now needed to clarify the mechanisms involved in the bimakalim-dobutamine interaction.

Limits of in vitro experimental models have to be considered. First, mechanical abnormalities, as seen in this model, may be different from contractile dysfunction caused by regional ischemia in in vivo models, which use the recovery of segmental wall function as an index of stunning. However, the reversibility 
of contractility loss in human atrial trabeculae under dobutamine challenge fulfills the definition of stunned myocardium. ${ }^{5,17}$ Second, although atrial and ventricular tissues have shown similar responses to hypoxia $^{12}$ and to positive inotropic stimulation, ${ }^{29}$ some tissue-related specificity may account for cardiac cell responses to action of $\mathrm{K}_{\text {ATP }}$ channel activators. ${ }^{15,30}$ Clinical extrapolation of our findings must therefore await further studies in human ventricular muscle.

\section{REFERENCES}

1. Damiano RJ. The electrophysiology of ischemia and cardioplegia: implications for myocardial protection. J Cardiol Surg 1995; 10:445-53.

2. Perrault LP, Menasché P, Bel A, de Chaumaray T, Peynet J, Mondry A, et al. Ischemic preconditioning in cardiac surgery: a word of caution. J Thorac Cardiovasc Surg 1996;112:1378-86.

3. Cole WC, McPherson CD, Sontag D. ATP-regulated $\mathrm{K}^{+}$channels protect the myocardium against ischemia/reperfusion damage. Circ Res 1991;69:571-81.

4. Speechly-Dick ME, Grover GJ, Yellon DM. Does ischemic preconditioning in the human involve protein kinase $\mathrm{C}$ and the ATP-dependent $\mathrm{K}^{+}$channel? Studies of contractile function after simulated ischemia in an atrial in vitro model. Circ Res 1995;77:1030-5.

5. Picard S, Criniti A, Iwashiro K, Rouet R, Monti F, Tonelli E, et al. Protection of human myocardium in vitro by $\mathrm{K}_{\mathrm{ATP}}$ activation with low concentration of bimakalim. J Cardiovasc Pharmacol 1999;34:162-72.

6. Auchampach JA, Maruyama M, Cavero I, Gross GJ. The new $\mathrm{K}^{+}$ channel opener aprikalim (RP 52891) reduces experimental infarct size in dogs in the absence of hemodynamic changes. J Pharmacol Exp Ther 1991;259:961-7.

7. McPherson CD, Pierce GN, Cole WC. Ischemic cardioprotection by ATP-sensitive $\mathrm{K}^{+}$channels involves high-energy phosphate preservation. Am J Physiol 1993;265:H1809-18.

8. Decking UKM, Reffelmann T, Schrader J, Kammermeier H. Hypoxia-induced activation of $\mathrm{K}_{\text {ATP }}$ channels limits energy depletion in the guinea pig heart. Am J Physiol 1995;269:H734-42.

9. Pignac J, Bourgouin J, Dumont L. Cold cardioplegia and the $\mathrm{K}^{+}$ channel modulator aprikalim (RP52891): improved cardioprotection in isolated ischemic rabbit hearts. Can J Pharmacol 1994; 72:126-32.

10. Dorman BH, Hebbar L, Hinton RB, Roy RC, Spinale FG. Preservation of myocyte contractile function after hypothermic cardioplegic arrest by activation of ATP-sensitive potassium channels. Circulation 1997;96:2376-84.

11. Sugimoto S, Puddu PE, Monti F, Schiariti M, Campa PP, Marino B. Pretreatment with the adenosine triphosphate-sensitive potassium channel opener nicorandil and improved myocardial protection during high-potassium cardioplegic hypoxia. J Thorac Cardiovasc Surg 1994;108:455-66.

12. Sugimoto S, Puddu PE, Monti F, Dawodu AA, del Monte F, Schiariti M, et al. Activation of ATP-dependent $\mathrm{K}^{+}$channels enhances myocardial protection due to cold high potassium cardioplegia: a force-frequency relationship study. J Mol Cell Cardiol 1995;27:1867-81.

13. Qiu Y, Galiñanes M, Hearse DJ. Protective effect of nicorandil as an additive to the solution for continuous warm cardioplegia. J Thorac Cardiovasc Surg 1995;110:1063-72.
14. Galiñanes M, Hearse DJ. Species differences in susceptibility to ischemic injury and responsiveness to myocardial protection. Cardioscience 1990;2:127-43.

15. Rouet R, Picard S, Criniti A, Monti F, Dawodu AA, Ruvolo G, et al. Effects of bimakalim on human cardiac action potentials: Comparison with guinea-pig and nicorandil and use-dependent study. J Cardiovasc Pharmacol 1999;33:255-63.

16. Puddu PE, Picard S, Iwashiro K, Criniti A, Dawodu AA, Monti F, et al. Contractile dysfunction following long (60 minutes) but not repeated short (5 minutes) hypoxia: a stunning model in isolated human atrial muscle. In: Puddu PE, Bing RJ, Campa PP, PooleWilson PhA, editors. Congestive heart failure: from basic science to therapeutics. Rome: Cardioricerca; 1997. p. 97-120.

17. Iwashiro K, Criniti A, Sinatra R, Dawodu AA, d'Amati G, Monti $\mathrm{F}$, et al. Felodipine protects human atrial muscle from hypoxiareoxygenation dysfunction: a force-frequency relationship study in an in vitro model of stunning. Int J Cardiol 1997;62:107-32.

18. Dawodu AA, Monti F, Iwashiro K, Schiariti M, Chiavarelli R, Puddu PE. The shape of human atrial action potential accounts for different frequency-related changes in vitro. Int J Cardiol 1996;54:237-49.

19. Paradise NF, Schmitter JL, Surmitis JM. Criteria for adequate oxygenation of isometric kitten papillary muscle. Am J Physiol 1981;241:H348-53.

20. Hearse DJ, Braimbridge MV, Jynge P. Cardioplegic solution in clinical use. In: Hearse DJ, Braimbridge MV, Jynge P, editors. Protection of the ischemic myocardium: cardioplegia. 1st ed. New York: Raven Press; 1982. p. 341-51.

21. Ryu KH, Tanaka N, Dalton N, Mao L, Rockman HA, Milano CA, et al. Force-frequency relations in the failing rabbit heart and responses to adrenergic stimulation. J Card Fail 1997;3:27-39.

22. Garlid KD, Paucek P, Yarov-Yarovoy V, Murray HN, Darbenzio $\mathrm{RB}$, D'Alonzo AJ, et al. Cardioprotective effects of diazoxide and its interaction with mitochondrial ATP-sensitive $\mathrm{K}^{+}$channels: possible mechanism of cardioprotection. Circ Res 1997;81:107282.

23. Jayawant AM, Lawton JS, Hsia P-W, Damiano RJ. Hyperpolarized cardioplegic arrest with nicorandil: advantages over other potassium channel openers. Circulation 1997;96 (Suppl):II-240-6.

24. Wilde AAM, Janse MJ. Electrophysiological effects of ATP sensitive potassium channel modulation: implications for arrhythmogenesis. Cardiovasc Res 1994;28:16-24.

25. Picard S, Rouet R, Ducouret P, Puddu PE, Flais F, Criniti A, et al. $\mathrm{K}_{\mathrm{ATP}}$ channels and "border zone" arrhythmias: role of the repolarization dispersion between normal and ischaemic ventricular regions. Br J Pharmacol 1999;127:1687-95.

26. Senior R, Buchner-Moell D, Raftery E, Lahiri A. Potent hemodynamic effects of bimakalim, a new potassium channel opener, in humans. J Cardiovasc Pharmacol 1993;22:717-21.

27. Garlid KD, Paucek P, Yarov-Yarovoy V, Sun X, Schindler PA. The mitochondrial $\mathrm{K}_{\text {ATP }}$ channel as a receptor for potassium channel openers. J Biol Chem 1996;271:8796-9.

28. Schwinger RHG, Böhm M, Mueller-Ehmsen J, Uhlmann R, Schmidt U, Staeblein A, et al. Effect of inotropic stimulation on the negative force-frequency relationship in the failing human heart. Circulation 1993;88:2267-76.

29. Böhm M, Diet F, Pieske B, Erdmann E. Screening of positive inotropic agents in isolated cardiac prepartions from different sources. J Pharmacol Methods 1989;21:33-44.

30. Ogbaghebriel A, Shrier A. Differential responsiveness of atrial and ventricular myocytes to potassium channel openers. J Cardiovasc Pharmacol 1995;25:65-74. 